\title{
BMJ Open Association between work schedules and motivation for lifestyle change in workers with overweight or obesity: a cross-sectional study in Japan
}

\author{
Yukihiro Tanikawa (D) , ${ }^{1}$ Miho Kimachi, ${ }^{1}$ Minoru Ishikawa, ${ }^{2}$ Tomoichiro Hisada, ${ }^{2}$ \\ Shunichi Fukuhara, ${ }^{1,3,4,5}$ Yosuke Yamamoto (D) ${ }^{1}$
}

To cite: Tanikawa Y, Kimachi M, Ishikawa M, et al. Association between work schedules and motivation for lifestyle change in workers with overweight or obesity: a cross-sectional study in Japan. BMJ Open 2020;10:e033000. doi:10.1136/ bmjopen-2019-033000

- Prepublication history and additional material for this paper are available online. To view these files, please visit the journal online (http://dx.doi org/10.1136/bmjopen-2019033000).

Received 16 July 2019 Revised 05 March 2020 Accepted 19 March 2020
D) Check for updates

(c) Author(s) (or their employer(s)) 2020. Re-use permitted under CC BY-NC. No commercial re-use. See rights and permissions. Published by BMJ.

For numbered affiliations see end of article.

\section{Correspondence to}

Dr Yosuke Yamamoto;

yamamoto.yosuke.5n@kyoto-u. ac.jp

\section{ABSTRACT}

Objective To investigate the association between work schedules and motivation for behavioural change of lifestyle, based on the transtheoretical model (TTM) in workers with overweight or obesity.

Design A cross-sectional observational study.

Setting A healthcare examination centre in Japan.

Participants Between April 2014 and March 2016, we recruited 9243 participants who underwent healthcare examination and met the inclusion criteria, namely, age 20-65 years, body mass index (BMI) $\geq 25 \mathrm{~kg} / \mathrm{m}^{2}$ and fulltime workers.

Exposure Night and shift (night/shift) workers were compared with daytime workers in terms of motivation for behavioural change.

Primary and secondary outcome measures The primary outcome was action and maintenance stages of change (SOC) for lifestyle in TTM. In a subgroup analysis, we investigated interactions between characteristics, including age, sex, BMl, current smoking, alcohol habits, hours of sleep and working hours.

Results Overall, 1390 participants (15.0\%) were night/shift workers; night/shift workers were younger (median age (IQR): 46 (40-54) vs 43 (37-52) years) and the proportion of men was lesser (75.4 vs $60.9 \%$ ) compared with daytime workers. The numbers of daytime and night/shift workers in the action and maintenance SOC were 2113 (26.9\%) and 309 (22.2\%), respectively. Compared with daytime workers, night/ shift workers were less likely to demonstrate action and maintenance SOC (adjusted OR (AOR): 0.85, 95\% Cl: 0.74 to 0.98). In a subgroup analysis that included only those with long working hours ( $\geq 10$ hours/day), results revealed a strong inverse association between night/shift work and action and maintenance SOC (AOR: 0.65, 95\% Cl: 0.48 to 0.86). A significant interaction was observed between long working hours and night/shift work ( $P$ for interaction=0.04). Conclusions In workers with overweight or obesity, a night/shift work schedule was associated with a lower motivation for behavioural change in lifestyle, and the association was strengthened in those with long working hours.

\section{INTRODUCTION}

Overweight and/or obesity is increasing worldwide, and is associated with higher
Strengths and limitations of this study

- This study examined the relationship between work schedules and motivation for behavioural change in workers with overweight or obesity.

- Our cross-sectional study includes a relatively large sample with little missing data, and will contribute to the improvement of lifestyle behaviours in night/ shift workers with overweight or obesity, particularly in those with long working hours.

- Our study has certain limitations: data were obtained from a single centre, data on socioeconomic factors were not obtained adequately and misclassification of work schedules may have occurred since the factors were assessed using a questionnaire.

risks of related complications including cardiovascular diseases, diabetes and certain cancers. ${ }^{12}$ In addition, overweight and/or obesity increases mortality and healthcarerelated costs. Therefore, the management of overweight and/or obesity is relevant to both, individual and public health. ${ }^{3}$

Although newer interventions, including bariatric surgery and pharmacotherapy have been introduced, lifestyle intervention remains one of the most effective management strategies for overweight and obesity. ${ }^{24}$ The transtheoretical model (TTM), one of the approaches for lifestyle intervention, is used to support the adoption of modifiable lifestyle behaviours. ${ }^{5-8}$ TTM stratifies patients into a series of five stages based on their motivation: precontemplation (no intent to change behaviour in the near future), contemplation (state their intent to change within the next 6 months), preparation (intends to change usually within the next months), action (overt modifications in one's lifestyles within the past 6 months) and maintenance (work to avoid relapse and are most often less tempted to deteriorate). ${ }^{9}$ Knowledge of 
patients' TTM stages assists healthcare providers in delivering appropriate support, and in assessing the circumstances for modifying their lifestyle behaviours. ${ }^{10}$ In a previous study, interventions individually arranged in accordance with patients' TTM stages led to weight loss, and were associated with the development of motivation for changes in lifestyle behaviours. ${ }^{8}$

Overweight and/or obesity is associated with various occupational factors, including the work schedule. Currently, about $20 \%$ of workers worldwide are believed to be working in night or shift schedules. ${ }^{11}{ }^{12}$ A metaanalysis including 28 studies indicated that night/shift work was associated with an increased risk of overweight and obesity. ${ }^{13} 14$

Several studies have found that poor motivation may be a barrier to behavioural change in adults with overweight and obesity. ${ }^{1415}$ Based on previous studies, it is possible that poor-worktime arrangements, such as long work hours and shift work, may discourage motivation for a healthy life and increase the risk of overweight and obesity through an unhealthy diet and reduced physical activity. ${ }^{16}$ However, little is known about the association between work schedules and behavioural change in workers with overweight or obesity.

In this study, we investigated the cross-sectional association between work schedules and change of lifestyle behaviours in workers with overweight or obesity. This was based on the relatively large volume of data from annual health check-up examinations in Japan.

\section{METHODS}

\section{Participants}

This was a cross-sectional observational study. We used the data from participants attending the Health Examination Centre of the Urasoe General Hospital between April 2014 and March 2016. More than 25000 individuals visit this centre to undergo annual examinations for health check-ups. All participants were asked about their work schedule, motivation for lifestyle change, healthrelated habits and medical history during each examination using standard self-administered questionnaires.

The inclusion criteria were as follows: age between 20 and 65 years, body mass index (BMI) $\geq 25 \mathrm{~kg} / \mathrm{m}^{2}$ and working full time. ${ }^{217-19}$ Subjects with missing information on stages of change (SOC) for lifestyle and work schedules, and pregnant women were excluded.

\section{Data collection}

We used a self-administered questionnaire to collect information regarding comorbidities, medications, lifestyle behaviours (eating, exercise, sleep, among others), work schedule, average working hours per day, habits of smoking and alcohol drinking and SOC for lifestyle. Height and weight were measured automatically at the study visit without shoes or heavy clothing in order to calculate BMI $\left(\mathrm{kg} / \mathrm{m}^{2}\right)$.

\section{Exposure}

The primary exposure was type of work schedule, which was categorised into two groups, namely, night/shift work and daytime work. Each participant was questioned on the working history based on a self-administered questionnaire, which included the work schedule (daytime work, night work, shift work and other employment, such as part-time jobs) and the average working hours per day (within $8,9,10,11$ and $\geq 12$ hours). In the questionnaire, participants were asked whether they were employed in daytime work, night work (permanent night shift, night and daytime shift), shift work and other employment (eg, part-time jobs). We categorised participants into two groups: participants who responded to 'daytime work' were considered to be 'daytime workers' and those who responded to 'night work' or 'shift work' were considered to be 'night/shift workers' respectively. In addition, we did not include participants who answered 'other employment' or not answered their work schedules.

\section{Outcomes}

In accordance with previous studies, the primary outcome was demonstration of action or maintenance stages for lifestyle based on TTM SOC. ${ }^{6820}$ We investigated the SOC for lifestyle using the same questionnaire. In the questionnaire, participants were asked about their motivation for behavioural change of lifestyle (eg, daily activity, eating behaviours) and instructed to choose from these answers which reflected five stages in TTM, as follows: 'I do not plan to change lifestyle behaviours during the next 6 months' (precontemplation), 'I am planning to change lifestyle behaviours during the next 6 months' (contemplation), 'I am planning to change lifestyle behaviours during the next month' (preparation), 'I have changed lifestyle behaviours for less than 6 months' (action) and 'I have changed lifestyle behaviours for more than 6 months' (maintenance).

\section{Statistical analysis}

To describe the characteristics of the groups, categorical variables have been presented as counts and percentages. Continuous variables with normal and skewed distributions have been presented as the mean (SD) and median (IQR) values, respectively. In order to evaluate the association between demonstration of action or maintenance SOC and work schedules (daytime vs night/shift), a multivariable logistic regression model was used to calculate the OR and the $95 \%$ CI. Adjustments were made for potential confounding factors including age ( $<40$ years vs $\geq 40$ years), sex, BMI $\left(25-29.9 \mathrm{~kg} / \mathrm{m}^{2}\right.$ vs $\left.\geq 30 \mathrm{~kg} / \mathrm{m}^{2}\right)$, comorbidities such as diabetes (defined as fasting plasma glucose $\geq 7.0$ $\mathrm{mmol} / \mathrm{L}(126 \mathrm{mg} / \mathrm{dL})$, postprandial plasma glucose $\geq 11.2$ $\mathrm{mmol} / \mathrm{L} \quad(200 \mathrm{mg} / \mathrm{dL}), \quad \mathrm{HbA1c} \geq 6.5 \%$, self-reported diabetes previously diagnosed by physicians or use of antidiabetic agents), ${ }^{21}$ coronary artery disease, cerebrovascular disorders, any cancer, current smoking (yes vs no), alcohol habits ( $<3$ times/week vs $\geq 3$ times/week), average working hours per day $(<10 \text { hours vs } \geq 10 \text { hours })^{22}$ and hours of sleep 
per day ( $<7$ hours vs $\geq 7$ hours). ${ }^{23}$ We also performed an analysis after re-categorising the work schedule into three groups, namely daytime, night and shift work, using the same model as that of the primary analysis.

Further, subgroup analyses for the main outcome, and interactions between work schedules and prespecified subgroups, which were thought to be important for possible interactions and clinical implications, were evaluated using multivariable logistic regression models. The subgroups were based on: age ( $<40$ vs $\geq 40$ years), sex, BMI (25.0-29.9 vs $\geq 30$ ), current smoking (yes vs no), alcohol habits ( $<3$ times/week vs $\geq 3$ times/week), hours of sleep ( $<7$ hours vs $\geq 7$ hours) and working hours ( $<10$ hours vs $\geq 10$ hours). In addition, interactions between work schedules and prespecified subgroups were evaluated in the multivariable logistic regression models.

We also performed secondary analysis to assess the relationship between work schedules and obesity-related lifestyle behaviours, namely, skipping breakfast ( $<3$ vs $\geq 3$ times/week), having dinner immediately before bedtime (dinner within 2 hours of bedtime; $<3$ vs $\geq 3$ times/week), taking snacks after dinner ( $<3$ vs $\geq 3$ times/week), drinking sweet beverages ( $<1$ vs $\geq 1$ bottle/day), eating until full, eating quickly and doing moderate exercise $(\geq 30 \mathrm{~min}$ moderate exercise more than twice a week for $\geq 1$ year; yes vs no). Since the missing data in the present study were $<5 \%$, we performed complete case evaluation for all multiple regression analyses. A two-tailed P-value $<0.05$ was considered to be statistically significant. All analyses were conducted using the Stata version 15.0 (Stata Corporation, College Station, TX, USA) software package.

\section{Patient and public involvement}

There was no patient and public involvement.

\section{RESULTS}

\section{Participant flow}

A total of 38029 participants underwent healthcare examinations between April 2014 and March 2016. We included 9263 participants who met the inclusion criteria; 20 participants who met the exclusion criteria were excluded. In addition, only $0.2 \%$ of participants $(n=20)$

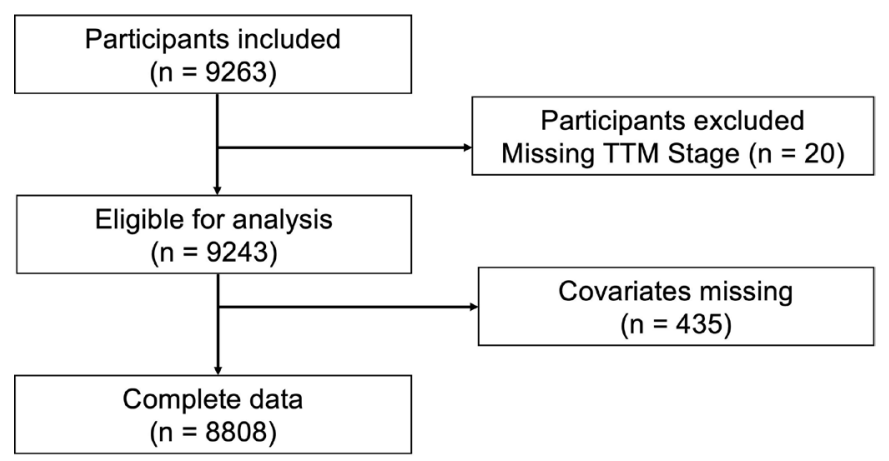

Figure 1 Flow diagram of the study. TTM, the transtheoretical model.
Table 1 Baseline characteristics stratified by work schedule

\begin{tabular}{|c|c|c|c|}
\hline & Total & $\begin{array}{l}\text { Daytime } \\
\text { workers }\end{array}$ & $\begin{array}{l}\text { Night shift } \\
\text { workers }\end{array}$ \\
\hline Participants & $n=9243$ & $\mathrm{n}=7853$ & $n=1390$ \\
\hline Male, n (\%) & $6765(73.2)$ & $5918(75.4)$ & 847 (60.9) \\
\hline Median age (IQR), years & $46(40-53)$ & $46(40-54)$ & $43(37-52)$ \\
\hline $\begin{array}{l}\text { Median BMI (IQR), kg/ } \\
\mathrm{m}^{2}\end{array}$ & $\begin{array}{l}27.3 \\
(26.0-29.6)\end{array}$ & $\begin{array}{l}27.3 \\
(26.0-29.5)\end{array}$ & $\begin{array}{l}27.7 \\
(26.1-30.0)\end{array}$ \\
\hline \multicolumn{4}{|l|}{ Comorbidities, n (\%) } \\
\hline Diabetes* & $1023(11.5)$ & $890(11.7)$ & $133(10.2)$ \\
\hline CAD & $141(1.5)$ & $129(1.6)$ & $12(0.9)$ \\
\hline CVD & $117(1.3)$ & $100(1.3)$ & $17(1.2)$ \\
\hline Cancer & $202(2.2)$ & $172(2.2)$ & $30(2.2)$ \\
\hline \multicolumn{4}{|l|}{ Hours of work, n (\%) } \\
\hline$\geq 10$ hours/day & $2753(29.9)$ & $2355(30.1)$ & $398(28.8)$ \\
\hline \multicolumn{4}{|l|}{ Hours of sleep, $n(\%)$} \\
\hline$<7$ hours/day & $7777(84.7)$ & $6612(84.8)$ & $1165(84.4)$ \\
\hline \multicolumn{4}{|l|}{ Alcohol habits, n (\%) } \\
\hline$\geq 3$ times/week & $4680(50.7)$ & $4097(52.2)$ & $583(42.0)$ \\
\hline \multicolumn{4}{|l|}{ Smoking status, n (\%) } \\
\hline Current smoker & $2498(27.0)$ & $2101(26.8)$ & $397(28.6)$ \\
\hline
\end{tabular}

*Diabetes was defined as fasting plasma glucose $\geq 7.0 \mathrm{mmol} / \mathrm{L}$ (126 mg/dL), postprandial plasma glucose $\geq 11.2 \mathrm{mmol} / \mathrm{L}(200 \mathrm{mg} /$ $\mathrm{dL}), \mathrm{HbA} 1 \mathrm{c} \geq 6.5 \%$, self-reported diabetes previously diagnosed by physicians, or the use of antidiabetic agents.

$\mathrm{BMI}$, body mass index; CAD, coronary artery disease; CVD, cerebrovascular disorder.

had absent information on TTM stage. The remaining 9243 patients were eligible for analysis (figure 1).

\section{Participant characteristics}

The demographic characteristics of the daytime and night/shift workers are shown in table 1 . The night and shift workers were combined for analysis in view of the sample sizes and cohort characteristics. Overall, the median age of the participants was 46 years, and $73.2 \%$ were male; the median BMI was 27.3. A total of 1390 participants $(15.0 \%)$ were night/shift workers. Compared with daytime workers, night/shift workers were younger (median age: 46 vs 43 years), had fewer male workers (75.4\% vs $60.9 \%$ ), had higher BMI (median: 27.3 vs 27.7 ) and reported lower alcohol intake (52.2\% vs $42.0 \%)$.

The characteristics of participants with missing covariates are shown in online supplementary table 1 . The majority of missing covariates were related to diabetes (341 participants).

\section{Association between work schedules and SOC for lifestyle based on TTM}

The primary outcome, demonstration of action and maintenance SOC for lifestyle, was observed in 2113 (26.9\%) and 309 (22.2\%) daytime and night/shift workers, respectively. Multivariable logistic regression showed that night/shift workers were less likely to demonstrate action 
Table 2 The association between work schedules and SOC for lifestyles based on TTM-OR for demonstration of action or maintenance stages

\begin{tabular}{lll} 
& Crude & Adjusted $^{\star}$ \\
\hline Participants & $\mathrm{n}=9243$ & $\mathrm{n}=8808$ \\
OR $(95 \% \mathrm{Cl})$ & $0.78(0.68$ to 0.89$)$ & $0.85(0.74$ to 0.98$)$ \\
\hline
\end{tabular}

*Adjusted for age ( $<40$ years vs $\geq 40$ years), sex, comorbidities (diabetes, CAD, CVD, cancer), BMI (25-29.9 kg/m² vs $\geq 30 \mathrm{~kg} / \mathrm{m}^{2}$ ), current smoking status (yes vs no), alcohol habits ( $<3$ times/week vs $\geq 3$ times/week), hours of sleep ( $<7$ hours vs $\geq 7$ hours), hours of work ( $<10$ hours vs $\geq 10$ hours).

$\mathrm{BMI}$, body mass index; CAD, coronary artery disease; CVD, cerebrovascular disorder; SOC, stage of change; TTM, the transtheoretical model.

or maintenance SOC than daytime workers (adjusted OR (AOR): $0.85,95 \%$ CI: 0.74 to 0.98 ) (table 2 ).

While recategorising the work schedule into three groups, the association was consistent with that of primary analysis; compared with daytime work, night work (AOR: 0.84, $95 \%$ CI: 0.66 to 1.07 ) and shift work (AOR: 0.85, $95 \%$ CI: 0.72 to 1.01 ) was associated with lesser action or maintenance SOC (online supplementary table 2).

\section{Subgroup analysis}

On subgroup analysis, the association between work schedules and demonstration of action and maintenance SOC did not differ by prespecified subgroups except for the longer work hour ( $\geq 10$ hours/day) subgroup (figure 2), when participants were limited to those with long working hours, results revealed a strong inverse association between night/shift work and action and maintenance SOC (AOR: $0.65,95 \%$ CI: 0.48 to 0.86 ). A significant interaction was observed between long working hours and night/shift work ( $P$ for interaction=0.04).

\section{Secondary analysis}

On secondary analysis, multivariable regression analyses showed that night/shift workers were more likely to have some lifestyle behaviours, namely, skipping breakfast, having dinner late, taking snacks after dinner and drinking sweet beverages (table 3 ).

\section{DISCUSSION}

In this observational study, we found that compared with daytime workers with overweight or obesity, those involved in night/shift work were less likely to be motivated to change their behaviour. There was a positive relationship between night/shift work and certain actual unhealthy lifestyle behaviours. When we assessed the interaction between work schedules and long working hours, the relationship between night/shift work and motivation for behavioural change was strengthened. In conjunction, these findings indicate that work schedules may be associated with the workers' motivation to modify

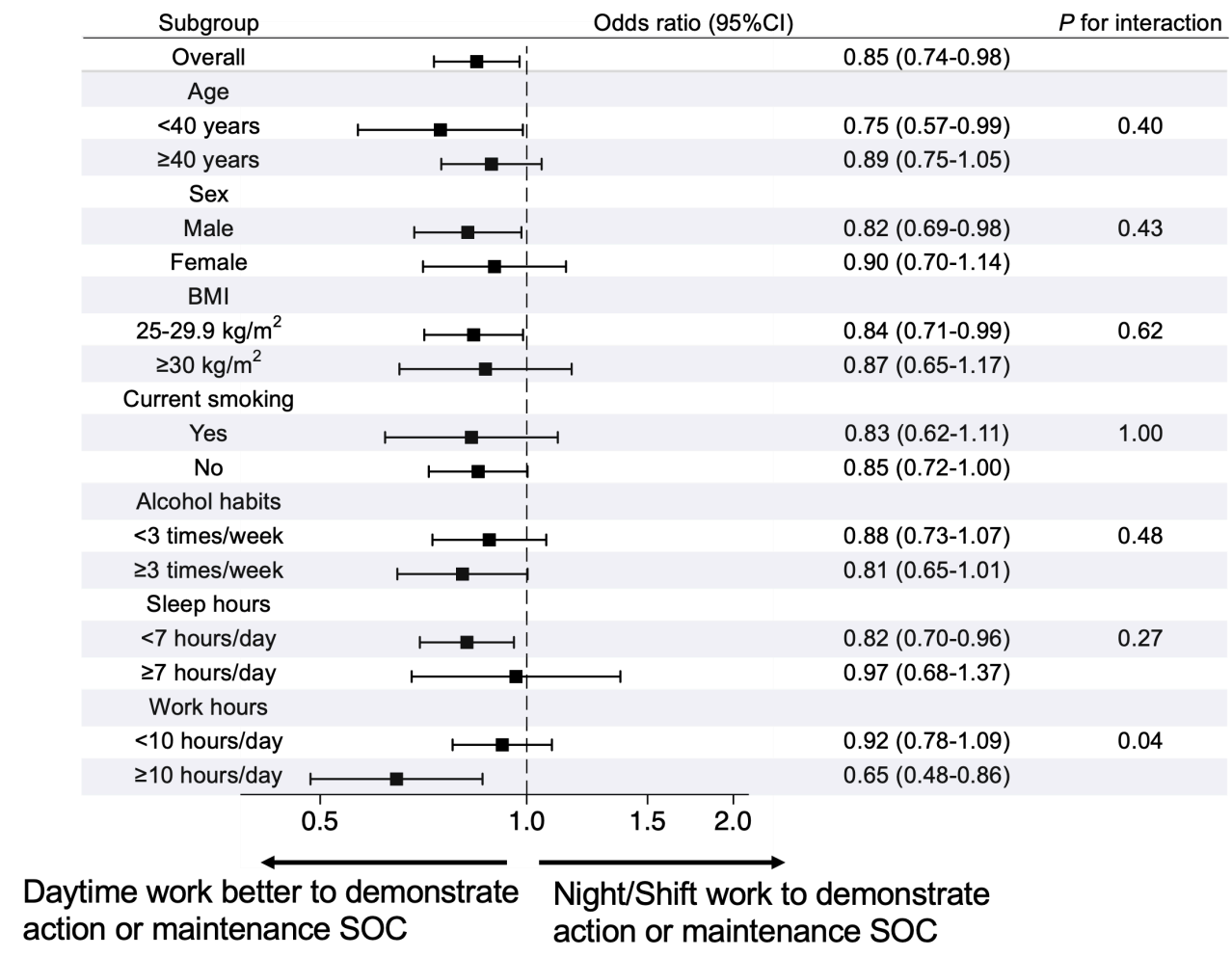

Figure 2 Adjusted ORs for primary outcome (demonstration of action or maintenance stages) in selected subgroups. "Each OR (for primary outcome: demonstration of action or maintenance stages) was adjusted for age ( $<40$ years vs $\geq 40$ years), sex, comorbidities (diabetes, CAD, CVD, cancer), BMI (25-29.9 kg/m² vs $\left.\geq 30 \mathrm{~kg} / \mathrm{m}^{2}\right)$, current smoking status (yes vs no), alcohol habits ( $<3$ times/week vs $\geq 3$ times/week), hours of sleep ( $<7$ hours vs $\geq 7$ hours), hours of work ( $<10$ hours vs $\geq 10$ hours). Interactions between work schedules and prespecified subgroups were evaluated in the multivariable logistic regression models. BMI, body mass index; CAD, coronary artery disease; CVD, cerebrovascular disorder; SOC, stages of change. 
Table 3 The association between work schedules and lifestyle behaviours-ORs $(95 \% \mathrm{Cl})$ in night/shift workers for each lifestyle behaviour

\begin{tabular}{lll}
\hline Lifestyle behaviours & Crude & Adjusted* \\
\hline $\begin{array}{l}\text { Skipping breakfast, } \geq 3 / \\
\text { week }\end{array}$ & $1.50(1.33$ to 1.69$)$ & 1.43 (1.25 to 1.63$)$ \\
$\begin{array}{l}\text { Having dinner immediately } \\
\text { before bedtime } \geq 3 / \text { week }\end{array}$ & $1.40(1.24$ to 1.57$)$ & 1.45 (1.27 to 1.64$)$ \\
$\begin{array}{l}\text { Taking snacks after dinner } \\
\geq 3 / \text { week }\end{array}$ & $1.36(1.17$ to 1.57$)$ & 1.25 (1.07 to 1.46$)$ \\
\hline $\begin{array}{l}\text { Drinking sweet beverages } \\
\geq 1 \text { bottle/day }\end{array}$ & $1.43(1.23$ to 1.65$)$ & $1.37(1.17$ to 1.61$)$ \\
\hline $\begin{array}{l}\text { Eating until full } \\
\text { Eating quickly }\end{array}$ & $1.17(1.03$ to 1.33$)$ & $1.13(0.99$ to 1.29$)$ \\
\hline $\begin{array}{l}\text { Doing moderate exercise } \\
\geq 2 / \text { week for } \geq 1 \text { year }\end{array}$ & $0.70(0.59$ to 0.83$)$ & 0.84 (0.70 to 1.01$)$ \\
\hline
\end{tabular}

*Adjusted for age ( $<40$ years vs $\geq 40$ years), sex, comorbidities (diabetes, CAD, CVD, cancer), BMI (25-29.9 kg/m² vs $\left.\geq 30 \mathrm{~kg} / \mathrm{m}^{2}\right)$, current smoking status (yes vs no), alcohol habits ( $<3$ times/week vs $\geq 3$ times/week), hours of sleep ( $<7$ hours vs $\geq 7$ hours), hours of work ( $<10$ hours vs $\geq 10$ hours).

BMI, body mass index; CAD, coronary artery disease; CVD, cerebrovascular disorder

their unhealthy behaviour, particularly in night/shift workers who engage in long hours of work.

To explain the relationship between work schedules and obesity, previous studies have focused on the endocrine mechanisms and circadian rhythm. ${ }^{16}{ }^{24}$ According to the endocrinal model, work-related stress may cause neuroendocrine stress, which leads to increased secretion of cortisol, catecholamines and interleukin- 6 , that may lead to fat accumulation, insulin resistance and lipid abnormalities. In addition, night/shift work disturbs the circadian rhythm, restricts sleep and increases neuroendocrine stress, which may cause overweight and obesity. Behavioural change is also an important factor to clarify this relationship. In terms of behavioural change, psychosocial stress induced by work-related stress may lead to an unhealthy lifestyle. ${ }^{16}$ Lower motivation for healthy lifestyle behaviours may indirectly increase the risk of weight gain and obesity. The factors include an unhealthy diet, which includes fatty and sweet foods, sedentary behaviour when not working and reduced sleep. Hence, motivation and lifestyle can be modifiable through behavioural pathways, some studies have described the progression of this development based on the hypothesis that the SOC (progressing to action and maintenance stages in TTM) may be closely associated with lifestyle and weight changes. One randomised controlled clinical trial reported that interventions focused on TTM led to a higher progression to action or maintenance stages, and a loss of body weight in obese participants. ${ }^{8}$ Another randomised controlled clinical trial found that TTM-based care significantly improved the lifestyle compared with usual care, which included factors such as calorie intake from fat, vegetable consumption and duration of exercise. ${ }^{620}$ In the present study, we found that night/shift workers were less motivated to change their lifestyles. Based on the previous results, a plausible explanation for the association found in the present study is that night/shift work may cause work-related stress, which is one of the factors known to lower motivation for changing an unhealthy lifestyle. Since TTM-based care addresses stress-related lifestyle issues, it is able to address the stress associated with night/shift work.

In the present study, in addition to the association between work schedules and motivation for healthy lifestyle, we also investigated the direct association between work schedules and various unhealthy lifestyle behaviours, namely, skipping breakfast, having dinner immediately before bedtime, taking snacks after dinner, eating until full, drinking sweet beverages, eating quickly and not doing moderate exercise. ${ }^{25-28}$ Among these unhealthy lifestyle behaviours, statistically significant associations were observed between night/shift work and skipping breakfast, having dinner immediately before bedtime, taking snacks after dinner and drinking sweet beverages. Although not significant, there was a tendency for night/ shift works to engage in several other unhealthy lifestyle behaviours, such as eating until full, eating quickly and not doing moderate exercise. Previous studies have revealed the association between obesity and unhealthy lifestyles. ${ }^{25-28}$ A possible explanation is that night/shift workers are forced to change their lifestyles for their work-related schedule, our results confirm that participants with overweight or obesity were at a higher risk of having unhealthy lifestyles if they were night/shift workers. Therefore, the present study indicates that night/shift workers with overweight or obesity require particular care. For example, advice for night/shift workers on topics such as eating patterns on night/shift work, timing of naps and sleeping patterns after night/ shift work might be useful. ${ }^{24} 29$

On subgroup analysis, we found that night/shift workers with overweight or obesity who work for long hours were less likely to demonstrate action or maintenance SOC. The P-value for interaction was statistically significant, suggesting that long working hours had an interaction effect on the association between night/ shift work and lower motivation for healthy lifestyles. Similar to night/shift work, long working hours increase the risk of overweight or obesity by the mechanism of endocrine pathway and behavioural pathways. In addition, systematic reviews have reported that shift workers have an increased risk of overweight or obesity ${ }^{13}{ }^{30}$; some studies have reported a positive association between long working hours and obesity. ${ }^{16} 3132$ However, these studies did not include work schedules. In view of the findings from these prior studies and knowledge on behavioural pathways, ${ }^{16}$ our findings suggest that night/shift workers with long working hours may be at a higher risk of overweight or obesity owing to difficulties in choosing a healthy lifestyle. Since night/shift workers are indispensable to society, they should avoid working for long hours to ensure good health. 
The present study has several strengths. First, our study includes a relatively large sample, with little missing data $(4.7 \%)$. Second, to the best of our knowledge, this is the first study to examine the relationship between work schedules and motivation for behaviour change in workers with overweight or obesity. Third, since we had data on both, work schedules and working hours, we could examine the relationship in detail, using interaction terms.

However, our study has limitations. First, our findings were based on cross-sectional evaluation. Associations found in our study did not confirm the causal relationship though motivation of workers may be less likely to affect work schedules. Second, in the questionnaire, SOC in TTM evaluated all aspects of the lifestyle, and was not restricted to overweight and obesity. Therefore, the responses to the SOC did not specifically reflect motivation related to overweight and obesity, but also to other unhealthy lifestyle behaviours, namely, smoking, drinking and shorter hours of sleep. We accordingly investigated the association of other unhealthy lifestyle behaviours during subgroup analysis. A similar tendency was noted irrespective of other unhealthy lifestyle behaviours. Third, since the work schedule was assessed by a questionnaire, a possibility of misclassification remains. For example, in our questionnaire, the participant might not clearly differentiate 'night work' and 'shift work' in their timetables. Therefore, some misclassification may have occurred between 'night work' and 'shift work'. However, any bias introduced by this misclassification in the primary analysis would be small. Fourth, adjustment using unmeasured confounders, such as education, income, detailed physical activity levels and type of work was not possible. Fifth, although there was a statistically significant relationship between work schedules and SOC in the main analysis, the difference between day and night/shift workers in the action or maintenance SOC was not substantially large $(4.7 \%)$. Finally, our cohort comprised individuals who underwent healthcare examinations at a single centre; therefore, these findings may not be generalised to other populations. Further studies including more diverse populations are warranted.

\section{CONCLUSIONS}

In conclusion, in workers with overweight or obesity, work schedules were found to be associated with motivation for behaviour change, particularly in those working for long hours. Further research is needed to understand the detailed association between work schedules, motivation and behaviour changes among various types of workers.

\footnotetext{
Author affiliations

${ }^{1}$ Department of Healthcare Epidemiology, School of Public Health in the Graduate School of Medicine, Kyoto University, Kyoto, Japan

${ }^{2}$ Health Examination Centre, Urasoe General Hospital, Urasoe, Japan

${ }^{3}$ Section of Clinical Epidemiology, Department of Community Medicine, Kyoto University, Kyoto, Japan
}

${ }^{4}$ Centre for Innovative Research for Communities and Clinical Excellence, Fukushima Medical University, Fukushima, Japan

${ }^{5}$ Shirakawa STAR for General Medicine, Fukushima Medical University, Fukushima, Japan

Acknowledgements The authors would like to thank Y. Uehara from the Healthcare Examination Centre Urasoe General Hospital, who assisted with data extraction and management, and all individuals who cooperated in conducting this study.

Contributors YT, MK, SF and YY designed the research. YT, MI and TH conducted the research. YT and YY analysed the data. YT, MK and YY prepared the manuscript. YT had primary responsibility for the final content. All the authors read and approved the final manuscript.

Funding The authors have not declared a specific grant for this research from any funding agency in the public, commercial or not-for-profit sectors.

Competing interests None declared.

Patient consent for publication Not required.

Ethics approval It adhered to the principles of the Declaration of Helsinki, and was approved by the ethics committee of the Kyoto University Graduate School and Faculty of Medicine (approval number: R-1345).

Provenance and peer review Not commissioned; externally peer reviewed. Data availability statement № additional data are available.

Open access This is an open access article distributed in accordance with the Creative Commons Attribution Non Commercial (CC BY-NC 4.0) license, which permits others to distribute, remix, adapt, build upon this work non-commercially, and license their derivative works on different terms, provided the original work is properly cited, appropriate credit is given, any changes made indicated, and the use is non-commercial. See: http://creativecommons.org/licenses/by-nc/4.0/.

\section{ORCID iDs}

Yukihiro Tanikawa http://orcid.org/0000-0002-5515-4950

Yosuke Yamamoto http://orcid.org/0000-0003-1104-2612

\section{REFERENCES}

1 NCD Risk Factor Collaboration (NCD-RisC). Trends in adult bodymass index in 200 countries from 1975 to 2014: a pooled analysis of 1698 population-based measurement studies with $19 \cdot 2$ million participants. Lancet 2016;387:1377-96.

2 Garvey WT, Mechanick Jl, Brett EM, et al. American association of clinical endocrinologists and American College of endocrinology comprehensive clinical practice guidelines for medical care of patients with obesity. Endocr Pract 2016;22:1-203.

3 Cawley J, Meyerhoefer C. The medical care costs of obesity: an instrumental variables approach. J Health Econ 2012;31:219-30.

4 Hansen S, Huttunen-Lenz M, Sluik D, et al. Demographic and social-cognitive factors associated with weight loss in overweight, pre-diabetic participants of the preview study. Int J Behav Med 2018;25:682-92

5 McGavock J, Durksen A, Wicklow B, et al. Determinants of readiness for adopting healthy lifestyle behaviors among Indigenous adolescents with type 2 diabetes in Manitoba, Canada: a crosssectional study. Obesity 2018;26:910-5.

6 Logue E, Sutton K, Jarjoura D, et al. Transtheoretical model-chronic disease care for obesity in primary care: a randomized trial. Obes Res 2005;13:917-27.

7 Mastellos N, Gunn LH, Felix LM, et al. Transtheoretical model stages of change for dietary and physical exercise modification in weight loss management for overweight and obese adults. Cochrane Database Syst Rev 2014;2:Cd008066.

8 Johnson SS, Paiva AL, Cummins CO, et al. Transtheoretical modelbased multiple behavior intervention for weight management: effectiveness on a population basis. Prev Med 2008;46:238-46.

9 Norcross JC, Krebs PM, Prochaska JO. Stages of change. J Clin Psychol 2011;67:143-54.

10 Krebs P, Norcross JC, Nicholson JM, et al. Stages of change and psychotherapy outcomes: a review and meta-analysis. J Clin Psychol 2018;74:1964-79.

11 Puttonen S, Viitasalo K, Härmä M. The relationship between current and former shift work and the metabolic syndrome. Scand J Work Environ Health 2012;38:343-8. 
12 Kubo T. [Estimate of the number of night shift workers in Japan]. J Uoeh 2014;36:273-6.

13 Sun M, Feng W, Wang F, et al. Meta-Analysis on shift work and risks of specific obesity types. Obes Rev 2018;19:28-40.

14 Burgess E, Hassmén P, Pumpa KL. Determinants of adherence to lifestyle intervention in adults with obesity: a systematic review. Clin Obes 2017;7:123-35.

15 Venditti EM, Wylie-Rosett J, Delahanty LM, et al. Short and long-term lifestyle coaching approaches used to address diverse participant barriers to weight loss and physical activity adherence. Int J Behav Nutr Phys Act 2014;11:16.

16 Solovieva S, Lallukka T, Virtanen M, et al. Psychosocial factors at work, long work hours, and obesity: a systematic review. Scand J Work Environ Health 2013;39:241-58.

17 WHO Expert Consultation. Appropriate body-mass index for Asian populations and its implications for policy and intervention strategies. Lancet 2004;363:157-63.

18 Jensen MD, Ryan DH, Apovian CM, et al. 2013 AHA/ACC/TOS guideline for the management of overweight and obesity in adults: a report of the American College of Cardiology/American heart association Task force on practice guidelines and the obesity Society. Circulation 2014;129:S102-38.

19 Examination Committee of Criteria for 'Obesity Disease' in Japan, Japan Society for the Study of Obesity. New criteria for 'obesity disease' in Japan. Circ J 2002;66:987-92.

20 Jones $\mathrm{H}$, Edwards L, Vallis TM, et al. Changes in diabetes self-care behaviors make a difference in glycemic control: the diabetes stages of change (disc) study. Diabetes Care 2003;26:732-7.

21 American Diabetes Association. 2. Classification and Diagnosis of Diabetes: Standards of Medical Care in Diabetes-2019. Diabetes Care 2019:42:S13-28.

22 Kuwahara K, Imai T, Miyamoto T, et al. Sleep duration modifies the association of overtime work with risk of developing type 2 diabetes
Japan epidemiology collaboration on occupational health study. $J$ Epidemiol 2018;28:336-40.

23 Consensus Conference Panel, Watson NF, Badr MS, et al. Joint consensus statement of the American Academy of sleep medicine and sleep research Society on the recommended amount of sleep for a healthy adult: methodology and discussion. J Clin Sleep Med 2015;11:931-52.

24 Faraut B, Bayon V, Léger D. Neuroendocrine, immune and oxidative stress in shift workers. Sleep Med Rev 2013;17:433-44.

25 Yoshida J, Eguchi E, Nagaoka K, et al. Association of night eating habits with metabolic syndrome and its components: a longitudinal study. BMC Public Health 2018;18:1366.

26 Kutsuma A, Nakajima K, Suwa K. Potential association between breakfast skipping and concomitant late-night-dinner eating with metabolic syndrome and proteinuria in the Japanese population. Scientifica 2014;2014:1-9.

27 Vissers D, Hens W, Taeymans J, et al. The effect of exercise on visceral adipose tissue in overweight adults: a systematic review and meta-analysis. PLoS One 2013;8:e56415

28 Richardson CR, Newton TL, Abraham JJ, et al. A meta-analysis of pedometer-based walking interventions and weight loss. Ann Fam Med 2008;6:69-77

29 Takada M. [Hygiene in Sleep: Problems of Sleeping Habits in Shift Workers]. Nihon Eiseigaku Zasshi 2018;73:22-6.

30 Amani R, Gill T, Shiftworking GT. Shiftworking, nutrition and obesity: implications for workforce health- a systematic review. Asia Pac J Clin Nutr 2013;22:505-15.

31 Ostry AS, Radi S, Louie AM, et al. Psychosocial and other working conditions in relation to body mass index in a representative sample of Australian workers. BMC Public Health 2006;6:53.

32 Lallukka T, Sarlio-Lähteenkorva S, Kaila-Kangas L, et al. Working conditions and weight gain: a 28-year follow-up study of industrial employees. Eur J Epidemiol 2008;23:303-10. 